\title{
Late Opacification of Foldable Intraocular Lenses
}

\author{
Jagat Ram, Nishant Gupta, Manish Chaudhary, Jaspreet Singh Sukhija, Amit Gupta, Jaidrath Kumar
}

\begin{abstract}
Objective: To report opacification of hydrophilic acrylic and silicone foldable intraocular lenses (IOL).

Designs: Case series.

Participants: Five patients with IOL opacification.

Results: We report five eyes of five patients with late opacification of the intraocular lens (IOL). Three patients had hydrophilic acrylic (SC60B-OUV-MDR, Inc), two had silicone IOL (Allergan SI30NB). Two out of the three patients with opacified hydrophilic acrylic IOLs had diabetes mellitus. Three eyes with opacified acrylic IOL underwent IOL exchange with hydrophobic acrylic IOL. Two silicone IOL patients had no visually significant opacification and were managed conservatively.
\end{abstract}

Conclusion: IOL optic opacification in hydrophilic acrylic and silicone IOL may be due to defective material, manufacturing process, storage.

Keywords: Opaque intraocular lens, Hydrophilic IOL, Silicone IOL, Diabetes mellitus, Late opacification of IOL.

How to cite this article: Ram J, Gupta N, Chaudhary M, Sukhija JS, Gupta A, Kumar J. Late Opacification of Foldable Intraocular Lenses. J Postgrad Med Edu Res 2012;46(2):95-97.

\section{Source of support: Nil}

Conflict of interest: None declared

\section{INTRODUCTION}

Small-incision cataract surgery with implantation of foldable intraocular lenses (IOL) has evolved significantly over the past two decades. Presently available foldable IOL biomaterials include silicone, hydrophobic acrylic and hydrophilic acrylic or hydrogel materials. ${ }^{1,2}$ Hydrogel lenses generally are manufactured from poly hydroxy-ethylmethacrylate (poly HEMA) and other copolymers hydrophilic acrylic. Various studies suggest that hydrogel lenses are biocompatible and resistant to yttrium-aluminiumgarnet laser damage. ${ }^{3}$ However, several cases of unacceptable opacification of the modern hydrophilic acrylic foldable IOL designs have been reported. ${ }^{4-7}$ In most of the cases, the opacification occurred on an average 2 years after surgery. ${ }^{4-7}$ Similarly, early and late opacification of silicone IOLs have been described. ${ }^{8-10}$ Here, we report five cases of opacification of IOL optic, 3 being hydrophilic acrylic and two silicone IOL.

\section{CASE REPORTS}

\section{Case 1}

A 68-year-old Indian male presented to us with complaint of blurring of vision in right eye for last 3 months. He underwent phacoemulsification with a hydrophilic acrylic IOL implantation (SC60B-OUV, MDR Inc.) in right eye 7 years back elsewhere and achieved 20/30 best corrected visual acuity (BCVA). He was a known case of diabetes mellitus for the last 10 years and was well controlled with oral medications.

On examination, his BCVA was 20/200 in right eye and 20/25 in left eye. Intraocular pressure (IOP) by Goldman applanation was 16 and $14 \mathrm{~mm} \mathrm{Hg}$ in right and left eye respectively. On slit lamp examination after dilatation, opacification of IOL optic was seen in right eye which was well placed in the capsular bag, an appearance similar to lamellar cataract (Fig. 1A). Fundus examination was normal. After written consent, patient underwent IOL exchange with hydrophobic acrylic IOL (AcrySof MA60AC). Due to poor capsular support, IOL was implanted in the sulcus. This patient developed postoperative corneal edema and hyphema which resolved in 2 weeks time. Final BCVA in the operated eye was 20/30.

Explanted IOL was single piece with opacification of optic seen on both sides. Edges of the optic as well as haptics were clear. Explanted IOL was subjected to chemical analysis by fourier transform infrared FTIR spectrophotometer (PE-RX1; Perkin Elmer). Spectrophotometer analysis of the explanted IOL showed typical absorption spectral bands that were suggestive of the materials being methacrylate polymer with hydroxyl groups. The infrared absorption bands were observed at 3431.3, 2923.9, 1634.3 and 1072 (Fig. 2). This suggested the IOL material as hydrophilic acrylic.

\section{Case 2}

A 55-year-old male presented with blurring of vision in left eye which started 2 years after phacoemulsification and implantation of a hydrophilic acrylic IOL (SC60B-OUV, MDR Inc.). Patient was a known case of diabetes mellitus under control on oral hypoglycemic.

On examination, his BCVA was 20/20 in the right and 20/80 in the left eye. Intraocular pressure recorded with Goldmann applanation tonometry was 16 and $18 \mathrm{~mm} \mathrm{Hg}$ in right and left eye respectively. Slit lamp examination of the left eye under pupillary dilatation revealed opacified single piece IOL in the capsular bag (Fig. 1B). There was no posterior capsular opacification (PCO). Right eye examination showed single piece IOL in the bag with no PCO. Posterior segment showed no diabetic retinopathy. After written informed consent, patient underwent IOL exchange with hydrophobic acrylic IOL (AcrySof MA60AC). Explanted IOL was single piece with opacification of optic seen on both sides. Edges of the optic as well as haptics were clear.

\section{Case 3}

A 63-year-old male presented with gradually progressive decrease in right eye vision since last 6 months. Patient had 
undergone right eye cataract surgery with implantation of hydrophilic acrylic IOL (SC60B-OUV, MDR Inc) 8 years back (operated somewhere else). He had no systemic illness and was not on any medications.

On examination, his BCVA was right 20/40 and left eye 20/20. IOP recorded with Goldmann applanation tonometry was $19 \mathrm{~mm} \mathrm{Hg}$ in right eye and $21 \mathrm{~mm} \mathrm{Hg}$ in left eye. Slit lamp examinatioin of right showed posterior chamber intraocular lens with crescent-shaped opacification of anterior surface of intraocualr lens and total opacification of posterior intraocular lens surface (Fig. 1C). Left eye showed posterior chamber IOL with no significant anterior or posterior capsular opacification. Posterior segment was within normal limits in both eyes.

After written informed consent, patient underwent IOL exchange with hydrophobic acrylic IOL (AcrySof MA60AC). Explanted IOL was single piece with asymmetric opacification of IOL optic seen on both sides. Anterior surface showed crescent shaped opacification and posterior surface being totally opacified. Postoperatively patient achieved BCVA of 20/30.

\section{Case 4}

A 75-year-old male presented with gradually progressive decrease in left eye vision since last 1 year. Patient had undergone left eye cataract surgery with implantation of Allergan SI30NB intraocular lens. He had no systemic illness and was not on any medications.

On examination, BCVA of the right eye was 20/20 and left eye 20/60. IOP recorded with Goldmann applanation tonometry was $19 \mathrm{~mm} \mathrm{Hg}$ in right eye and $21 \mathrm{~mm} \mathrm{Hg}$ in left eye. Slit lamp examination of left showed posterior chamber IOL with petalloid pattern of opacification of the IOL optic not involving the visual axis (Fig. 1D). There was visually significant PCO in the left eye. Right eye showed posterior chamber IOL with no significant anterior or posterior capsular opacification. Posterior segment was within normal limits in both eyes. He underwent Nd:YAG capsulotomy of left eye with subsequent improvement in BCVA to 20/30.

\section{Case 5}

A 73-year-old female on regular follow-up for diabetic retinopathy was examined with dot like white opacities distributed all over the IOL optic. Patient is a known diabetic on oral hypoglycemic agents with well controlled blood sugars. Patient had undergone left eye cataract surgery with implantation of Allergan SI30BN intraocular lens 10 years earlier. Patient was not on any other systemic medications.

On examination, her BCVA was right eye 20/200 and left eye 20/200. IOP recorded with Goldmann applanation tonometry was $21 \mathrm{~mm} \mathrm{Hg}$ in both eyes. Vision was poor because of macular edema and epiretinal membrane in right and left eye respectively. Slit lamp examination of left eye under dilatation revealed whitish dot like opacities distributed all over the optic of three piece silicone intraocular lens (Fig. 1E). Right eye revealed three piece acrylic lens with clear optic. There was no visually significant anterior or posterior capsular opacification.

Our major criteria for exchange of IOL were as follows:

i. Decrease in the best corrected visual acuity for distance by at least three lines.

ii. Decrease in corrected near visual acuity N8 or less.

iii. Failure to visualize fundus due to IOL opacification.

All three patients had improved in BCVA after the IOL exchange. Most common complication in this series was corneal edema (1 eye), hyphema (1 eye). In case 1 , IOL was implanted in sulcus and, other two cases, IOL was implanted in the bag.

\section{DISCUSSION}

Opacification of the optic of the IOL of different biomaterial has been reported by various authors around the world. ${ }^{1-12}$ Hydrophilic acrylic IOLs are manufactured from different acrylic copolymers with varying water contents. Different physical and biologic properties of each acrylic material result from only small alterations of the side groups of the standard methacrylate polymer backbone. ${ }^{1}$ Main advantages of hydrophilic acrylic IOLs are the possibility for better

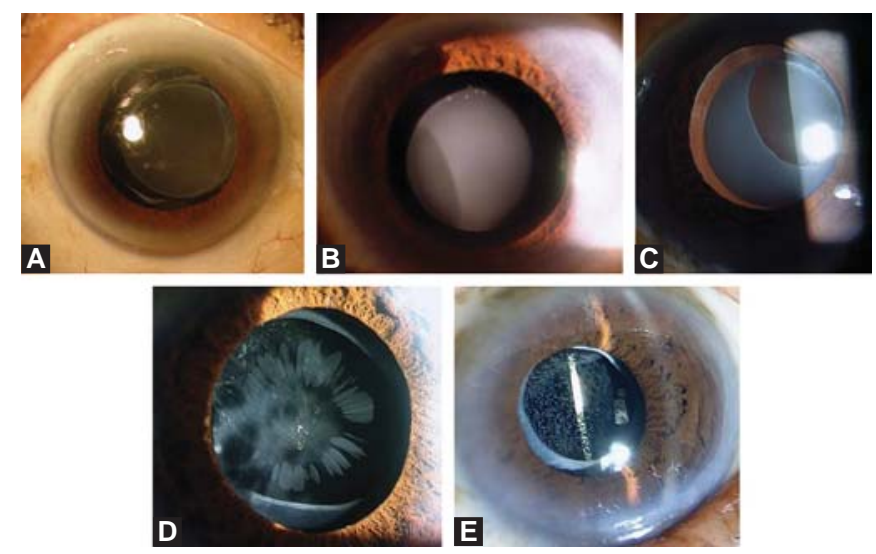

Figs $1 \mathrm{~A}$ to $\mathrm{E}$ : These eyes implanted with foldable intraocular lens (IOL) after successful phacoemulsification developed opacification of IOL several years later, leading to severe visual loss. The clinical picture in all eyes simulated cataract

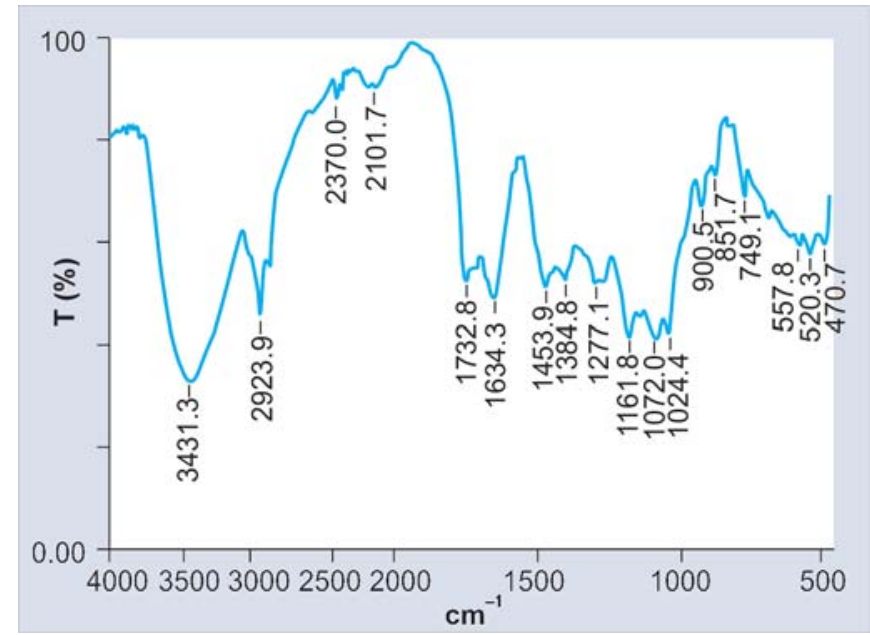

Fig. 2: FTIR spectrophotometry of the IOL showing the absorption bands corresponding to methacrylate polymer 
tolerance, high uveal biocompatibility and less inflammatory cytological response compared with hydrophobic acrylic. ${ }^{2,3}$ However, the most frequently explanted IOLs today are hydrogel lenses. Late postoperative opacification of hydrophilic acrylic IOLs has been reported widely in the literature with several materials and designs. ${ }^{4-7}$

Average time between IOL implantation and opacification reported in the literature varied from 11 to 46 months. ${ }^{4-7}$ Exact cause of delayed opacification is not known. It may be due to metabolic changes and alteration in blood-aqueous barrier because of diabetes mellitus. Opacification of IOL has been reported in diabetic patients. ${ }^{5}$ In case 1 , fourier transform infrared (FTIR) spectrophotometry of explanted IOL suggested hydrophilic acrylic material of explanted foldable IOL. ${ }^{8}$

Although PCO is the most common late complication of phacoemulsification with PCIOL implantation, ${ }^{13,14}$ opacification of IOL itself is another important cause of delayed decrease in visual acuity after cataract surgery and IOL implantation especially with hydrophilic acrylic IOLs. ${ }^{3-}$ ${ }^{7}$ IOL exchange remains the preferred options for managing these patients. Early and late opacification of silicone IOLs is a well recognized complication reported by various authors. ${ }^{10-12}$ Hydration of lens material leading to early opacification of silicone IOL optic have been described. ${ }^{10,12}$ Some manufacturers have reported that aerosolized cleaning solution, insecticides and disinfections adsorbed over the IOL can promote influx of the water into the IOL. ${ }^{10}$ Some manufactures suggested that opacification may be related to low molecular weight silicone fractions that were not crosslinked during the curing process that can lead to the lens hydration. ${ }^{12}$ Coating of the silicone lens with silicone oil used during vitreoretinal surgery produces optical irregularities. ${ }^{12}$ There are reports of late opacification of silicone IOL in patients on long-term amiodarone and rifabutin therapy and after Nd:YAG capsulotomy in eyes with asteroid hyalosis. ${ }^{10}$ The eyes with significantly reduced vision require IOL exchange.

\section{CONCLUSION}

We describe five cases of IOL optic opacification, 3 hydrophilic acrylic and 2 silicone IOL. Spectrophotometric evaluation of one of the explanted IOL revelated it to be acrylic in nature. Various factors related to IOL manufacturing, storage, surgical technique and adjuvants may be involved in the process of IOL opacification. Opacification may be observed intraoperatively, early or late postoperatively. Further investigation is warranted to ascertain other possible causes of this phenomenon.

\section{REFERENCES}

1. Chehade M, Elder MJ. Intraocular lens materials and styles: A review. Aust N Z J Ophthalmol 1997;25:255-63.

2. Kohnen $\mathrm{T}$. The variety of foldable intraocular lens materials. J Cataract Refract Surg 1996:22 (suppl);1255-58.

3. Schauersberger J, Kruger A, Abela C, Müllner-Eidenböck A, Petternel V, Svolba G, et al. Course of postoperative inflammation after implantation of 4 types of foldable intraocular lenses. J Cataract Refract Surg 1999;25:1116-20.

4. Werner L, Apple DJ, Kaskaloglu M, Pandey SK. Dense opacification of the optical component of a hydrophilic acrylic intraocular lens: A clinicopathological analysis of 9 explanted lenses. J Cataract Refract Surg 2001;27:1485-92.

5. Pandey SK, Werner L, Apple DJ, Kaskaloglu MM. Hydrophilic acrylic intraocular lens optic and haptics opacification in a diabetic patient: Bilateral case report and clinicopathological correlation. Ophthalmology 2002;109:2042-51.

6. Kleinmann G, Mamalis N, Apple DJ, Assia EI. Opacification of the acryl C160 hydrophilic acrylic intraocular lens. J Cataract Refract Surg 2006;32:367-68.

7. Oner HE, Durak I, Saatci OA. Late postoperative opacification of hydrophilic acrylic intraocular lenses. Ophthalmic Surg Lasers 2002;33:304-08.

8. Hendra PJ. Laser-Raman spectra of polymers. Adv Polymer Sci 1969;6:151-69.

9. Werner L. Causes of intraocualar lens opacification or discolouration. J Cataract and Refract Surg 2007;33:713-26.

10. Elgohary Mostafa, Zaheer A, Werner L, Ilionides A, Sheldrick James, Ahmed Nisar. Opacification of SA40N silicone multifocal intraocular lens. J Cataract and Refract Surg 2007;33: 342-47.

11. Koch DD, Heit LE. Discolouration of silicone intraocular lens. Arch Ophthalmol 1992;110:119-20.

12. Apple DJ, Federman JL, Krolicki TJ. Irreversible silicone oil adhesion to intraocular lens; clinicopathological analysis. Ophthalmology 1996; 103:1555-61.

13. Ram J, Kaushik S, Brar GS, Gupta A. Neodymium: YAG capsulotomy rates following phacoemulsification with implantation of PMMA, silicone, and acrylic intraocular lenses. Ophthalmic Surg Lasers 2001;32:375-82.

14. Ram J, Panday S, Apple DJ, Werner L, Brar GS, Singh R, et al. Effect of in-the-bag intraocular lens fixation on the prevention of posterior capsule opacification. J Cataract Refract Surg 2001; 27:1039-46.

\section{ABOUT THE AUTHORS}

\section{Jagat Ram (Corresponding Author)}

Professor, Advanced Eye Centre, Postgraduate Institute of Medical Education and Research, Chandigarh-160012, India, Phone: 091-9876081419, Fax: 091-172-2774437, e-mail: drjagatram@gmail.com

\section{Nishant Gupta}

Senior Resident, Advanced Eye Centre, Postgraduate Institute of Medical Education and Research, Chandigarh, India

\section{Manish Chaudhary}

Assistant Professor, Advanced Eye Centre, Postgraduate Institute of Medical Education and Research, Chandigarh, India

\section{Jaspreet Singh Sukhija}

Assistant Professor, Advanced Eye Centre, Postgraduate Institute of Medical Education and Research, Chandigarh, India

\section{Amit Gupta}

Advanced Eye Centre, Postgraduate Institute of Medical Education and Research, Chandigarh, India

\section{Jaidrath Kumar}

Senior Resident, Advanced Eye Centre, Postgraduate Institute of Medical Education and Research, Chandigarh, India 